\title{
Kv3.1b Is a Novel Component of CNS Nodes
}

\author{
Jérôme Devaux, ${ }^{1,6}$ Gisèle Alcaraz, ${ }^{2}$ Judith Grinspan, ${ }^{3}$ Vann Bennett, ${ }^{4}$ Rolf Joho, ${ }^{5}$ Marcel Crest, ${ }^{6}$ and Steven S. Scherer ${ }^{1}$ \\ ${ }^{1}$ Department of Neurology, The University of Pennsylvania Medical Center, Philadelphia, Pennsylvania 19104-6077, ${ }^{2}$ Institut National de la Santé et de la \\ Recherche Médicale Unité 464, Institut Jean Roche, Faculté de Médecine Nord, Université de la Méditerranée, 13916 Marseille Cedex 20, France, ${ }^{3}$ Division \\ of Neurology Research, Children's Hospital of Philadelphia, Philadelphia, Pennsylvania 19104-6077, ${ }^{4}$ Howard Hughes Medical Institute and Departments of \\ Biochemistry and Cell Biology, Duke University Medical Center, Durham, North Carolina 27710, ${ }^{5}$ Center for Basic Neuroscience, The University of Texas \\ Southwestern Medical Center, Dallas, Texas 75390-9111, and ' ${ }^{2}$ aboratoire Intégration des Informations Sensorielles, Centre National de la Recherche \\ Scientifique, 13402 Marseille Cedex 20, France
}

We herein demonstrate that Kv3.1b subunits are present at nodes of Ranvier in the CNS of both rats and mice. Kv3.1b colocalizes with voltage-gated $\mathrm{Na}^{+}$channels in a subset of nodes in the spinal cord, particularly those of large myelinated axons. Kv3.1b is abundantly expressed in the gray matter of the spinal cord, but does not colocalize with $\mathrm{Na}^{+}$channels in initial segments. In the PNS, few nodes are Kv3.1b-positive. During the development of the CNS, Kv3.1b clustering at nodes occurs later than that of $\mathrm{Na}^{+}$channels, but precedes the juxtaparanodal clustering of Kv1.2. Moreover, in myelin-deficient rats, which have severe CNS dysmyelination, node-like clusters of $\mathrm{Kv} 3.1 \mathrm{~b}$ and $\mathrm{Na}^{+}$channels are observed even in regions devoid of oligodendrocytes. Ankyrin $\mathrm{G}$ coimmunoprecipitates Kv3.1b in vivo, indicating that these two proteins may interact in the CNS at nodes. 4-Aminopyridine, a $\mathrm{K}^{+}$channel blocker, broadened the compound action potential recorded from adult rat optic nerve and spinal cord, but not from the sciatic nerve. These effects were also observed in $\mathrm{Kv} 3.1$-deficient mice. In conclusion, $\mathrm{Kv} 3.1 \mathrm{~b}$ is the first $\mathrm{K}^{+}$channel subunit to be identified in CNS nodes; but Kv3.1b does not account for the effects of 4-aminopyridine on central myelinated tracts.

Key words: Shaw; potassium channels; oligodendrocyte; Schwann cells; myelin; multiple sclerosis

\section{Introduction}

The distribution of ion channels in the axonal membrane of mammalian myelinated fibers is sharply defined (Arroyo and Scherer, 2000; Peles and Salzer, 2000; Rasband and Shrager, 2000). In both the CNS and the PNS, voltage-gated $\mathrm{Na}^{+}\left(\mathrm{Na}_{\mathrm{v}}\right)$ channels are concentrated at nodes of Ranvier, whereas Kv1.1 and $\mathrm{Kv} 1.2 \mathrm{~K}^{+}$channels are concentrated in the juxtaparanodal regions, separated from $\mathrm{Na}_{\mathrm{v}}$ channels by paranodal septate-like junctions. The localization of these ion channels is maintained by specific interactions with the axonal cytoskeleton. The anchoring of $\mathrm{Na}_{\mathrm{v}}$ channels requires their interaction with ankyrin $\mathrm{G}$ (Jenkins and Bennett, 2001, 2002), but does not require paranodal septate-like junctions (Bhat et al., 2001; Boyle et al., 2001; Mathis et al., 2001; Arroyo et al., 2002). By contrast, the juxtaparanodal localization of the Kv1.1/1.2 depends on the integrity of paranodal septate-like junctions (Dupree et al., 1999; Bhat et al., 2001; Boyle et al., 2001; Arroyo et al., 2002; Honke et al., 2002; Marcus et al., 2002).

Multiple $\mathrm{K}^{+}$currents have been recorded in myelinated PNS axons, called I-, F-, and S-type currents. The I-type current has characteristics similar to those mediated by Kv1.1 and Kv1.2 (Safronov et al., 1993; Reid et al., 1999), including sensitivity to the $\mathrm{K}^{+}$channel blocker 4-aminopyridine (4-AP). The sequestration of Kv1.1 and Kv1.2 under the myelin sheaths in developing

Received Aug. 22, 2002; revised Feb. 21, 2003; accepted March 12, 2003.

This study was supported by the Charcot-Marie-Tooth Association and National Institutes of Health Grant R01 NS43174. We thank Dr. Maurice Gola for critical assistance.

Correspondence should be addressed to Dr. Jerome Devaux, Room 460, Stemmler Hall, 36th Street and Hamilton Walk, The University of Pennsylvania Medical Center, Philadelphia, PA 19104-6077.E-mail: jdevaux@mail.med.upenn.edu. Copyright $\odot 2003$ Society for Neuroscience $\quad 0270-6474 / 03 / 234509-10 \$ 15.00 / 0$ nerves correlates with the diminishing effects of 4-AP (Vabnick et al., 1999). In adults, 4-AP has weak effects on myelinated fibers (Kocsis et al., 1983), leading only to the appearance of reexcitation in sensory fibers (Eng et al., 1988). In agreement with the idea that Kv1.1 and Kv1.2 are the 4-AP-sensitive channels of PNS myelinated fibers, the absence of Kv1.1 also results in abnormal re-excitation of adult myelinated axons (Zhou et al., 1998, 1999).

In contrast to the PNS, 4-AP broadens the action potential (AP) of myelinated fibers in the mature CNS, suggesting that some $\mathrm{K}^{+}$subunits may be localized in nodes, and are involved in repolarization (Gordon et al., 1988; Devaux et al., 2002). Kv1.1 and Kv1.2 are unlikely to mediate these effects of 4-AP, because they are sequestered under the myelin sheath as in the PNS (Rasband et al., 1999b). Although nodal Kv subunits have not been described, F-type currents have some pharmacological and electrophysiological similarities with members of the Shaw family (Rettig et al., 1992), especially Kv3.1 and Kv3.2. We investigated this issue, and herein describe that Kv3.1b subunits are present at many CNS nodes. The nodal clustering of Kv3.1b occurs later than that of the $\mathrm{Na}_{\mathrm{v}}$ channels during development, but precedes the clustering of Kv1.2 in the juxtaparanode. Node-like clusters of Kv3.1b were seen in myelin-deficient $(m d)$ rats, which have severe CNS dysmyelination, indicating that the maintenance of Kv3.1b clusters does not require septate-like junctions. Kv3.1b coimmunoprecipitated with ankyrin $\mathrm{G}$ in brain membranes, suggesting a direct or indirect interaction between these proteins. Because 4-AP broadened the compound action potential (CAPs) of the optic nerve in both normal and Kv3.1-deficient mice to the same extent, Kv3.1b alone did not seem to mediate the effect of 
4-AP. We conclude that Kv3.1b is a novel component of CNS nodes.

\section{Materials and Methods}

Animals. Postnatal day 21 (P21) male $m d$ rats (which have obvious tremor and gait difficulties) and their wild-type (WT) male littermates were obtained from a colony at the University of Pennsylvania. Threemonth-old Kv3.1-deficient mice (mixed genetic background 129/Sv $\times$ C57BL/6) were obtained from a colony at the University of Texas Southwestern Medical Center (Ho et al., 1997).

Immunostaining. 129/Sv mice or Wistar rats were overdosed with pentobarbital and decapitated with a guillotine. The spinal cords and optic nerves were removed, embedded in OCT, and frozen. Cryostat sections $(5-10 \mu \mathrm{m})$ were cut, thaw mounted on SuperFrost Plus glass slides (Fisher Scientific, Pittsburgh, PA) and stored at $-20^{\circ} \mathrm{C}$. The sciatic nerves were placed in ice-cold PBS and teased into small bundles on SuperFrost Plus glass slides, dried overnight at room temperature (RT), and stored at $-20^{\circ} \mathrm{C}$. Sections and teased fibers were permeabilized by immersion in $-20^{\circ} \mathrm{C}$ acetone for $10 \mathrm{~min}$, blocked at RT for at least $1 \mathrm{hr}$ in $5 \%$ fish skin gelatin containing $0.5 \%$ Triton X-100 in PBS, and incubated overnight at $4^{\circ} \mathrm{C}$ with the primary antibodies diluted in blocking solution. Rabbit antisera against Kv3.1b or Kv3.2 (\#APC-014, diluted 1:100; Alomone Labs, Jerusalem, Israel), and mouse monoclonal antibodies raised against Kv1.2 (diluted 1:100; Upstate Biotechnology, Lake Placid, NY), MAG (513, diluted 1:100; Boehringer Mannheim, Indianapolis, IN), and Pan$\mathrm{Na}_{\mathrm{v}}$ channels (diluted 1:50; Sigma, St. Louis, $\mathrm{MO}$ ) were used. After incubating with the primary antibodies, the slides were washed, incubated with the appropriate fluorescein- and rhodamine-conjugated donkey cross-affinity-purified secondary antibodies (diluted 1:100; Jackson ImmunoResearch, West Grove, PA), and mounted on glass slides with Vectashield (Vector Laboratories, Burlingame, CA). The slides were examined by epifluorescence with the appropriate filters on a Leica DMR light microscope and photographed with a Hamamatsu (Tokyo, Japan) digital camera, followed by image manipulation with Adobe Photoshop (Adobe Systems, San Jose, CA). For the quantitative study, transverse sections of thoracic spinal cord from two mice were immunolabeled for $\mathrm{Kv} 3.1 \mathrm{~b}$ and $\mathrm{PanNa}_{\mathrm{v}}$ channel. The diameters of every node stained with $\mathrm{PanNa}_{\mathrm{v}}$ channel antibody were measured using the software Image-Pro Plus (Media Cybernetics, Silver Spring, MD), and each node was scored as Kv3.1b-positive or Kv3.1b-negative. Nodes were binned according to their diameter; measurements are represented as means \pm SD.

The specificity of Kv3.1b antisera was demonstrated using a preabsorption experiment. One microgram of antiserum was mixed with $5 \mu \mathrm{g}$ of its cognate peptide, and was incubated for $1 \mathrm{hr}$ at RT according to the manufacturer's instructions. Then slides of mouse spinal cord were labeled with both $\mathrm{PanNa}_{\mathrm{v}}$ channels and "blocked" Kv3.1b antisera. Total disappearance of the labeling for Kv3.1b was observed (data not shown).

Coimmunoprecipitation and immunoblotting. Brain and spinal cord membrane were prepared by a modification of the method of Hartshorne and Catterall (1984). The brains and spinal cords from adult 129/Sv mice or Wistar rats were minced, homogenized in ice-cold $0.32 \mathrm{M}$ sucrose, 5 $\mathrm{mm}$ Tris/ $\mathrm{HCl}, \mathrm{pH} 7.4$, plus protease inhibitors (2 mм EDTA, $0.5 \mathrm{~mm}$ amidinophenylmethanesulfonyl fluoride, $1 \mu \mathrm{g} / \mathrm{ml}$ of aprotinin, pepstatin $A$ and leupeptin), and centrifuged at $750 \times g$ for $10 \mathrm{~min}$. Supernatants (S1) were sedimented at $17,000 \times g$ for $60 \mathrm{~min}$. The pellet $(\mathrm{P} 2)$ was lysed in $1 \mathrm{~mm}$ EDTA, $5 \mathrm{~mm}$ Tris/HCl, $\mathrm{pH}$ 8.2, plus protease inhibitors, homogenized, and sedimented at $27,000 \times g$ for $40 \mathrm{~min}$. The pellet (P3), a brain membrane preparation, was solubilized in $1.25 \%$ Triton X-100, $0.1 \mathrm{~mm}$ $\mathrm{KCl}, 10 \mathrm{~mm}$ Tris/ $\mathrm{HCl}, \mathrm{pH}$ 7.4, plus protease inhibitors, stored on ice for $15 \mathrm{~min}$ and centrifuged at $27,000 \times \mathrm{g}$ for $60 \mathrm{~min}$. The supernatant (S4) was incubated with the primary antibody overnight at $4^{\circ} \mathrm{C}$ in the presence of $0.1 \%$ BSA. Two hundred micrograms of protein were incubated with $13.3 \mu \mathrm{l}$ of rabbit antisera against Kv3.1b or Kv3.2, with $4 \mu \mathrm{l}$ of mouse monoclonal antibodies raised against Kv1.2, or with $4 \mu \mathrm{l}$ of affinitypurified rabbit antiserum against ankyrin G. Extracts were incubated with $30 \mu \mathrm{l}$ of protein $\mathrm{G}$-agarose (Invitrogen, Carlsbad, CA) during 30 $\min$ at $4^{\circ} \mathrm{C}$. After washing three times with $0.1 \%$ Triton $\mathrm{X}-100,1 \% \mathrm{BSA}$, $0.1 \mathrm{~mm} \mathrm{KCl}, 10 \mathrm{~mm}$ Tris/HCl, $\mathrm{pH}$ 7.4, and protease inhibitors, the bound proteins were released by boiling in $20 \mu \mathrm{l}$ of SDS sample buffer for $2 \mathrm{~min}$.
The released proteins were separated in a 5\% SDS-PAGE gel, then electrotransferred to polyvinylidene difluoride (PVDF) membranes. After blocking with 5\% nonfat milk in PBS for $1 \mathrm{hr}$, membranes were incubated with a rabbit antiserum against Kv3.1b (1:500), Kv3.2 (1:500), or ankyrin $\mathrm{G}(1 / 1000)$ at $4^{\circ} \mathrm{C}$ overnight. After several rinses, the PVDF
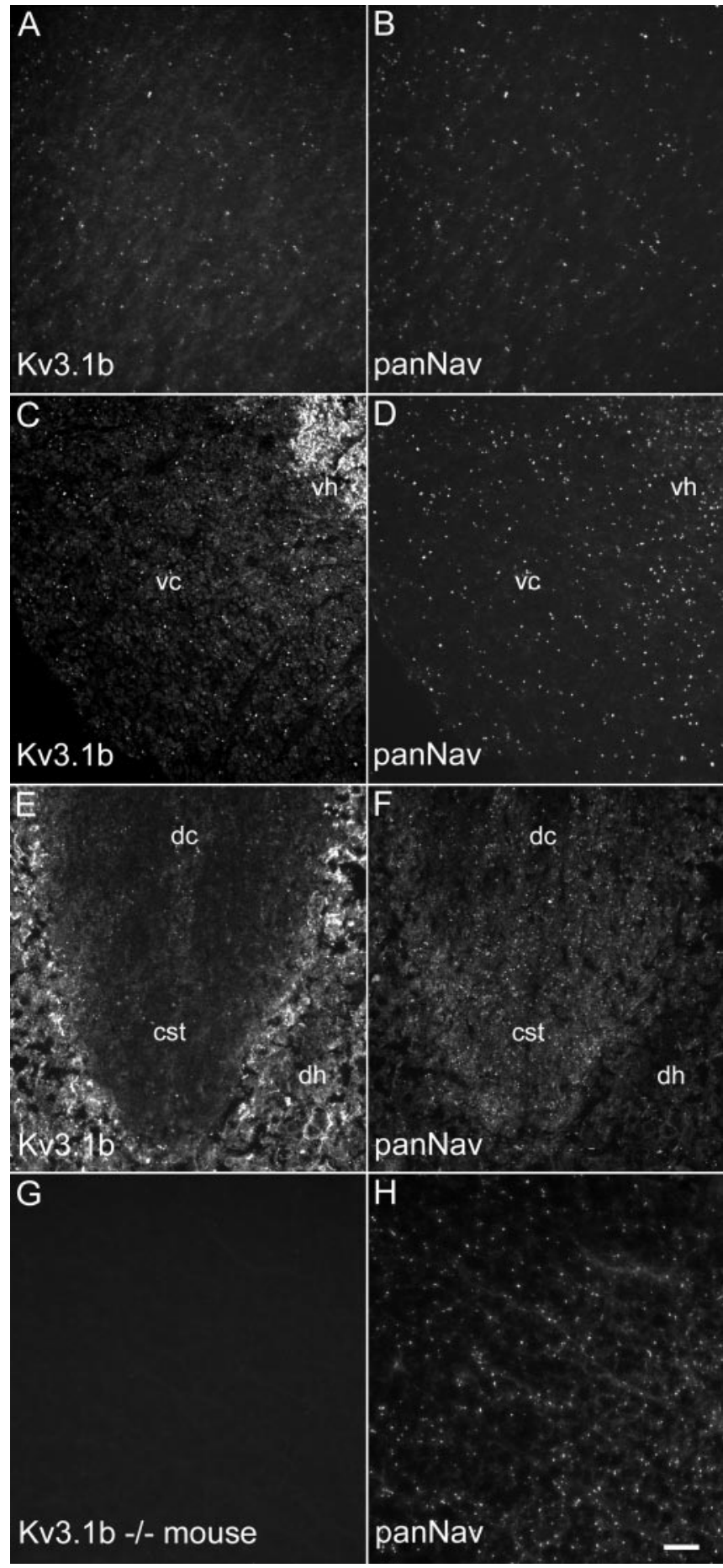

Figure 1. Localization of Kv3.1b in the adult mouse spinal cord. Transverse sections of unfixed thoracic spinal cord were double labeled with a rabbit Kv3.1 b antiserum [tetramethylrhodamine isothiocyanate (TRITC)] and a "pan" monoclonal antibody (FITC) against $\mathrm{Na}_{\mathrm{v}}$ channels $\left(\right.$ panNa $\left.\mathrm{v}_{\mathrm{v}}\right)$. In the lateral $(A, B)$ and ventral $(C, D)$ columns of the spinal cord, the majority of the nodes were double labeled, but in the dorsal column (dc) and especially in the corticospinal tract (cst) $(E, F)$, only a subset of nodes were Kv3.1b-positive. Note the intense staining for Kv3.1b in the dorsal horn (dh) and ventral horn (vh) of the spinal cord. In Kv3.1-deficient (-I-) mouse, no labeling was observed for Kv3.1b (the ventral column is shown) $(G, H)$. Scale bar, $20 \mu \mathrm{m}$. 


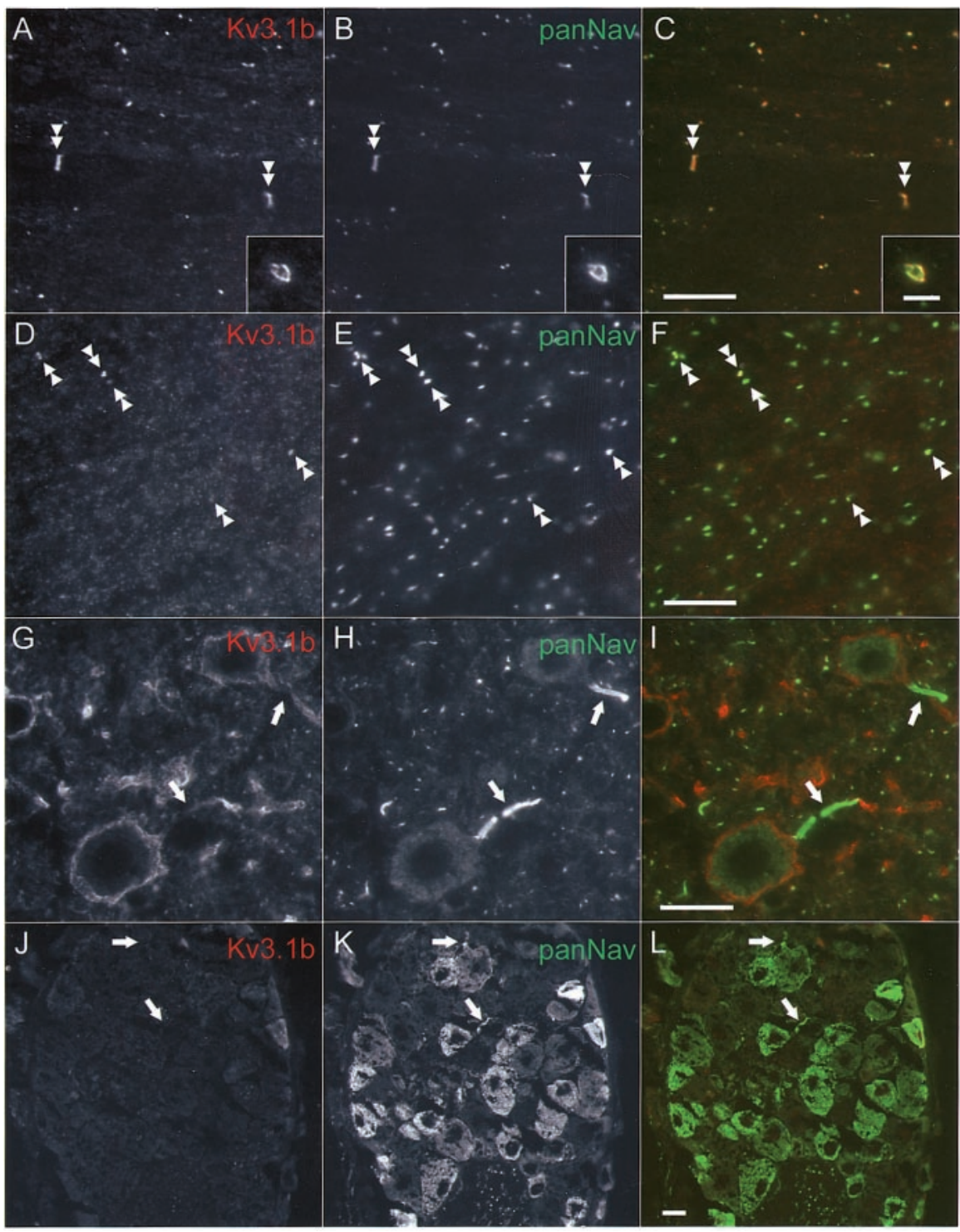

Figure 2. Kv3.1b labeling in adult mouse spinal cord, optic nerve, and DRG. Longitudinal sections of the ventral column $(A-C)$ and dorsal horn $(G-I)$ of the spinal cord, as well as optic nerve $(D-F)$ and DRG $(J-L)$, double-labeled with a rabbit Kv3.1b antiserum (TRITC) and a monoclonal antibody (FITC) against $\mathrm{Na}_{v}$ channels (panNa $a_{v}$ ) are shown. In $A-C$, Kv3.1b is colocalized exclusively with $\mathrm{Na}_{\mathrm{v}}$ channels in the nodes (double arrowheads). The inset shows a node in a transverse section. In $D-F$, few nodes were Kv3.1b-positive. In G-I, Kv3.1b appears to be expressed, at least in part, in the somatic membrane of neurons, but was not colocalized with $\mathrm{Na}_{v}$ channels in the initial segments (arrows). In $J-L$, many somata expressed $\mathrm{Na}_{v}$ channels, but few expressed Kv3.1b. Arrows indicate initial segments. Scale bars: (in $C$ ) $A-C, 20 \mu \mathrm{m}$; (in F) $D-F$, $20 \mu \mathrm{m}$; (in I) $G-I, 20 \mu \mathrm{m}$; (in L) $J-L, 20 \mu \mathrm{m}$; (in C, inset) $A-C$, insets, $5 \mu \mathrm{m}$.

membrane was incubated with horseradish peroxidase-conjugated donkey anti-rabbit secondary antibody (1:5000; Jackson ImmunoResearch), washed several times, and the signal was revealed using ECL Plus (Amersham Biosciences, Arlington Heights, IL) according to the manufacturer's instructions. For immunoblots of brain and spinal cord, tissues were prepared as described above, and the P3 pellet was solubilized in SDS sample buffer and heated for $2 \mathrm{~min}$ at $90^{\circ} \mathrm{C}$. For optic and sciatic nerves, tissues were diced into small pieces, and heated in SDS sample buffer for 4 min at $90^{\circ} \mathrm{C}$, and insoluble material was removed by centrifugation at $10,000 \mathrm{rpm}$ for $10 \mathrm{~min}$. For each tissue, $100 \mu \mathrm{g}$ of protein was loaded on $7.5 \%$ SDS-PAGE, and proteins were treated as described above. Protein concentrations were determined using a Bio-Rad (Hercules, CA) kit.

Comparison of the cytoplasmic binding sites for ankyrin $G$ of several proteins to the cytoplasmic domain of $K v 3.1 b$. The homology of sequences between $\mathrm{Kv} 3.1 \mathrm{~b}$ and the consensus binding sites for ankyrin $\mathrm{G}$ found in several L1 CAM family members, $\alpha-\mathrm{Na}^{+}, \mathrm{K}^{+}$-ATPase, and CD44 were determined using BLAST searches for the following sequences: ESDDSLVDYGEGGEGQFNEDGSFIGQY for L1 CAM (Zhang et al., 1998a), NGGNGTVEDRKPSEL for CD44 (Bourguignon et al., 1998), and SYYQEAKSSKIMESFKNMVPQQALV for $\alpha-\mathrm{Na}^{+}, \mathrm{K}^{+}$ATPase (Zhang et al., 1998b). No homologies were found between these sequences and that of Kv3.1b.

Electrophysiology. Wistar rats, 129/Sv mice, or Kv3.1-deficient mice were overdosed with pentobarbital and decapitated with a guillotine. The optic nerves, a $2 \mathrm{~cm}$ length of the proximal sciatic nerve (from the fusion of the L4 and L5 roots to the sciatic notch) or a $3 \mathrm{~cm}$ length of cervical spinal cord were quickly dissected out and transferred into artificial CSF (ACSF). Sciatic nerves were desheathed to maximize drug access, and cervical spinal cords were hemisected and the ventral funiculus was dissected out. All these tissues were incubated in ACSF for a $60 \mathrm{~min}$ equilibrium period before recording, and were kept at $37^{\circ} \mathrm{C}$ during the experiment, oxygenated in a $95 \% \mathrm{O}_{2}$ and $5 \%$ $\mathrm{CO}_{2}$ atmosphere, and perfused at a flow rate of 1-2 $\mathrm{ml} / \mathrm{min}$ with ACSF. For optic nerve recording, the nerve was drawn into two suction ACSF-filled glass electrodes. CAPs were evoked by applying a supramaximal stimulus ( $40 \mu \mathrm{sec}$ duration) at the distal nerve end and were recorded from the second electrode at the proximal end. For sciatic nerves and spinal cord, the tissues were mounted in a three-compartment recording chamber, where the proximal and distal ends of the nerve are isolated by petroleum jelly. The distal end was stimulated by a supramaximal stimulation (10 $\mu$ sec duration) through two electrodes isolated with petroleum jelly and recording were performed the same way from the proximal end. The signals were amplified, digitized at $500 \mathrm{~Hz}$, and stored on a hard disk. The effects of 4-AP (Sigma) were measured 30-45 min after its application, once the effects had reached a steady state. For recruitment analysis, nerves were stimulated at increasing intensity, and the amplitude of the CAPs was measured and plotted as a function of the stimulation intensity. For the refractory period analysis, two successive stimuli were applied at different intervals. The amplitude of the second CAPs was then measured and plotted as a function of the delay between the two stimuli. The ACSF contained the following (in $\mathrm{mM}$ ): 126 $\mathrm{NaCl}, 3 \mathrm{KCl}, 2 \mathrm{CaCl}_{2}, 2 \mathrm{MgSO}_{4}, 1.25 \mathrm{NaH}_{2} \mathrm{PO}_{4}$ $26 \mathrm{NaHCO}_{3}$, and 10 dextrose, $\mathrm{pH}$ 7.4-7.5.

\section{Results}

\section{$\mathrm{Kv} 3.1 \mathrm{~b}$ is localized to the nodes of Ranvier in the CNS}

The Kv3.1 gene gives rise to two distinct channel subunits, Kv3.1a and Kv3.1b, by alternative splicing (Luneau et al., 1991). Their predicted protein sequences diverge only at their $\mathrm{C}$ terminals. We focused on Kv3.1b because it is far more abundant than Kv3.1a in the adult rat brain (Perney et al., 1992; Gan and Kaczmarek, 1998). Our preliminary investigations revealed that cryosections of unfixed spinal cord have stronger Kv3.1b staining than do tissues fixed with either 4\% paraformaldehyde or Zamboni's fixative, and that the gray matter was strongly stained. To localize the nodes of Ranvier, we stained transverse sections of unfixed 
adult mouse spinal cord with a rabbit antiserum against $\mathrm{Kv} 3.1 \mathrm{~b}$ or $\mathrm{Kv} 3.2$ and $\mathrm{a}$ mouse monoclonal antibody that recognizes a sequence common to all $\mathrm{Na}_{\mathrm{v}}$ channel $\alpha$ subunits. Weak Kv3.2 staining was seen in the spinal cord gray matter, but not in the white matter (data not shown). As shown in Figure $1 A-F$, numerous nodes were labeled for $\mathrm{Kv} 3.1 \mathrm{~b}$ in all white matter tracts, but the proportion of Kv3.1bpositive nodes differed (Fig. $2 A$ ). In the lateral column (Fig. 1 $A, B$ ) and the ventral funiculus (Fig. 1C,D), nearly all nodes were colabeled for $\mathrm{Na}_{\mathrm{v}}$ and $\mathrm{Kv} 3.1 \mathrm{~b}$ channels. In contrast, in the corticospinal tract (Fig. $1 E, F$ ), relatively fewer nodes were labeled for Kv3.1b. When observed at high magnification, Kv3.1b and $\mathrm{Na}_{\mathrm{v}}$ channels staining appeared circular, confirming that they were expressed at nodes (Fig. $3 A-C$, insets). Moreover, in longitudinal sections, Kv3.1b staining precisely matched that of $\mathrm{Na}_{\mathrm{v}}$ channels (Fig. 3A-C, double arrowheads). The staining for Kv3.1b was specific because it was abolished by preincubating the antiserum with the peptide (data not shown). Furthermore, no Kv3.1b staining was found in Kv3.1-deficient mice (Fig. $1 G, H$ ), which lack both Kv3.1a and Kv3.1b isoforms (Ozaita et al., 2002).

We suspected that the reason for the variation in nodal staining was the variation in the composition of axons in different tracts. In particular, the size of myelinated axons appeared to correlate with Kv3.1b nodal staining. The CST contains many small myelinated axons (Hildebrand, 1972; Murray and Blakemore, 1980; Chung and Coggeshall, 1987), whereas the ventral and lateral funiculi contain many large myelinated axons. To address this issue, we immunostained sections of mouse and rat optic nerves, which mainly contain small myelinated fibers (Matheson, 1970), and found that 14\% of the nodes were labeled for Kv3.1b. The nodes that were stained appeared to have a larger diameter than the unlabeled nodes (Fig. $3 D-F$ ). To confirm that $\mathrm{Kv} 3.1 \mathrm{~b}$ expression is related to the diameter of the fibers, a quantitative study was performed, and the number of nodes and Kv3.1b-positive nodes relative to the diameter range of the nodes was measured. We found that almost every node with a diameter $>1.8 \mathrm{~mm}$ was $\mathrm{Kv} 3.1 \mathrm{~b}$-positive, whereas 54 to $93 \%$ of the nodes having a diameter $<1.8 \mathrm{~mm}$ were Kv3.1b-positive (Fig. $2 \mathrm{~B}$ ). These data support a relationship between the axonal diameter and the nodal localization of Kv3.1b. However, because small nodes in the ventral funiculus are more often Kv3.1b-positive than those in the dorsal funiculus (Fig. 3C,D), it appears that other factors also influence the expression of Kv3.1b.

Because nodes and initial segments both have ankyrin $G$ and $\mathrm{Na}_{\mathrm{v}}$ channels, we determined whether Kv3.1b was expressed in initial axonal segments by labeling longitudinal sections of the spinal cord as well as sections of dorsal root ganglia. Although the gray matter was intensely labeled (likely corresponding to surface staining of somata and presynaptic terminals) (Sekirnjak et al., 1997), initial segments were not stained (Fig. 3G-I). The sensory neurons in the dorsal ganglia, in contrast, had little Kv3.1b staining; this may be related to the absence of synapses on their cell bodies (Fig. 3J-L). As in the spinal cord, the initial segments of sensory neurons were Kv3.1b-negative.

\section{Localization of Kv3.1b and Kv3.2 in the PNS}

We examined the localization of Kv3.1b and $\mathrm{Kv} 3.2$ in teased fibers from adult mouse sciatic nerves. PNS nodes were Kv3.2negative (data not shown), and only $23 \%$ of the nodes expressed Kv3.1b (Fig. 4A,B); the labeling even in these nodes was less intense than that in the CNS. When it was possible to follow single fibers, we observed that all of the nodes were either stained or unstained, suggesting that Kv3.1b was expressed in a specific subset of fibers, perhaps related to their function. To elucidate this point, we stained teased fibers from both the dorsal and the
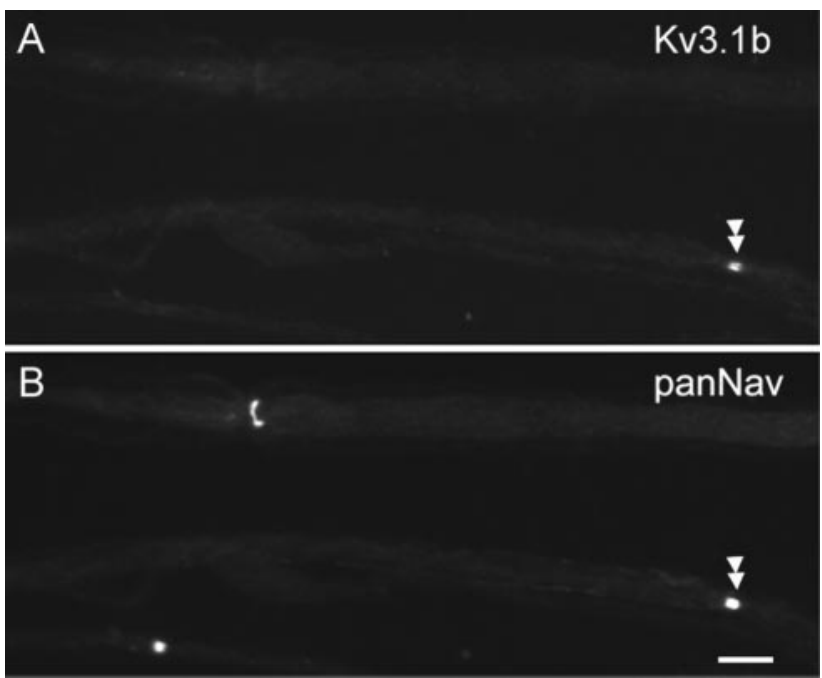

Figure 4. Few PNS nodes express Kv3.1b. Unfixed teased fibers from adult mouse sciatic nerve were double labeled with a rabbit Kv3.1b antiserum (TRITC, $A$ ) and a monoclonal antibody against $\mathrm{Na}_{\mathrm{v}}$ channels (FITC, B). One Kv3.1b-positive node is indicated (double arrowheads); two other nodes are Kv3.1b-negative. Scale bar, $10 \mu \mathrm{m}$. 

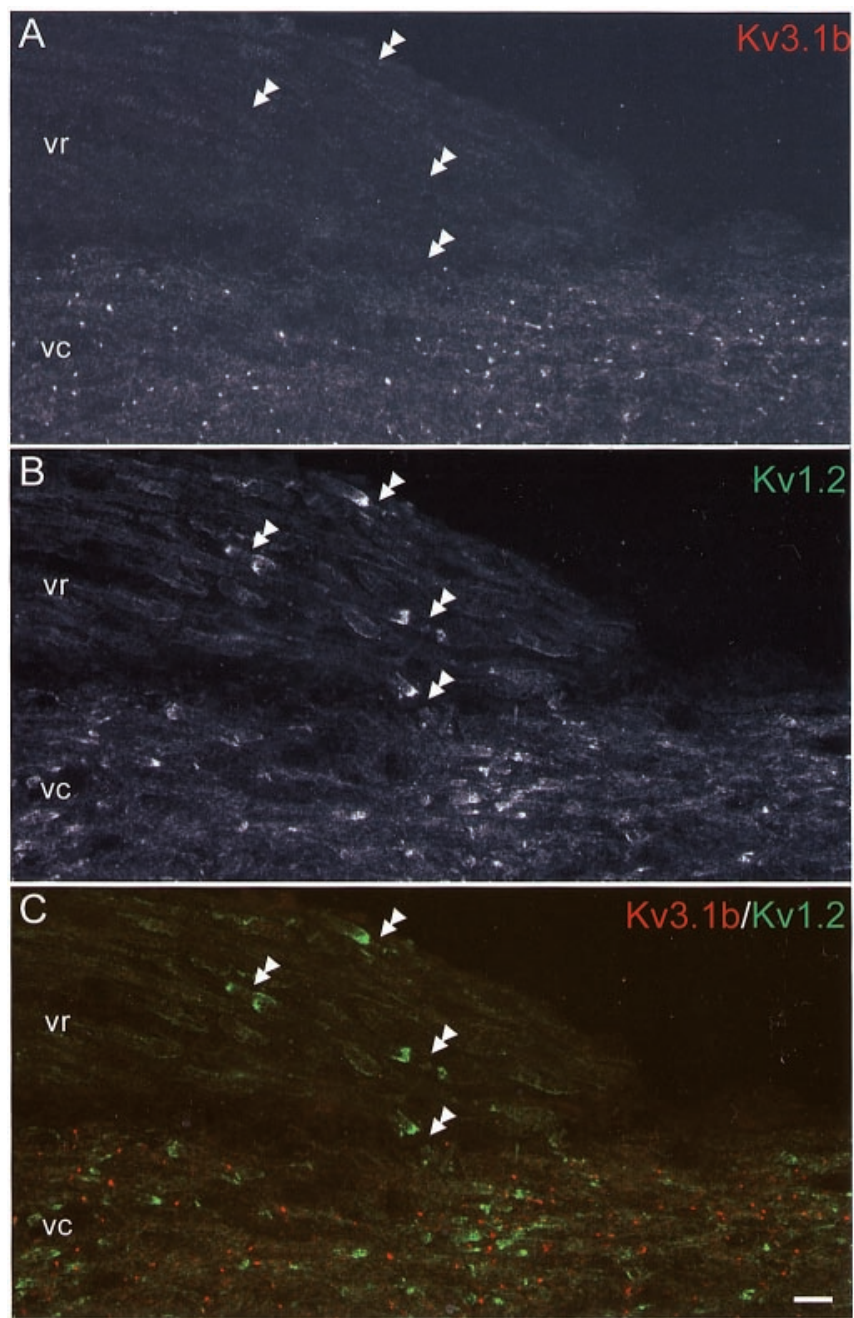

Figure 5. Differential localization of Kv3.1b and Kv1.2 in CNS axons. These are images of longitudinal sections of the ventral column (vc) of unfixed lumbar spinal cord from adult mice. In the spinal cord, the narrow band of nodal Kv3.1b staining (TRITC; $A$ ) is flanked by two broader regions of juxtaparanodal Kv1.2 staining (FITC; $B$ ). C, Merge. Note the relative lack of labeling for Kv3.1b in the PNS nodes (double arrowheads) of the ventral rootlet (vr). Scale bar, $10 \mu \mathrm{m}$.

ventral roots, but found Kv3.1-positive nodes in both smalland large-diameter fibers of the dorsal and ventral roots (data not shown). We also examined the development of Kv3.1b expression in the dorsal and ventral roots. At $\mathrm{P} 4$ and $\mathrm{P} 8$, no nodal staining was observed; some clusters were observed at P12, and many more at P15 and P21 (data not shown). These observations exclude the possibility that PNS nodes lose expression of Kv3.1 during development. Thus, the functional significance of Kv3.1b-positive PNS nodes remains to be established.

Because motor and sensory neurons have myelinated fibers with both CNS and PNS myelin, we examined sections of the ventral root entry zone, the transition zone between CNS and PNS myelin for motor fibers. Sections colabeled for Kv3.1b and Kv1.2 show that Kv3.1b-positive nodes are found in the spinal cord but not in the roots, whereas Kv1.2-positive juxtaparanodes were found in both places (Fig. $5 A-C$ ). Thus, the strong nodal labeling of Kv3.1b in motor axons appears to depend on some aspect of the CNS environment, presumably related to either oligodendrocytes or astrocytes.

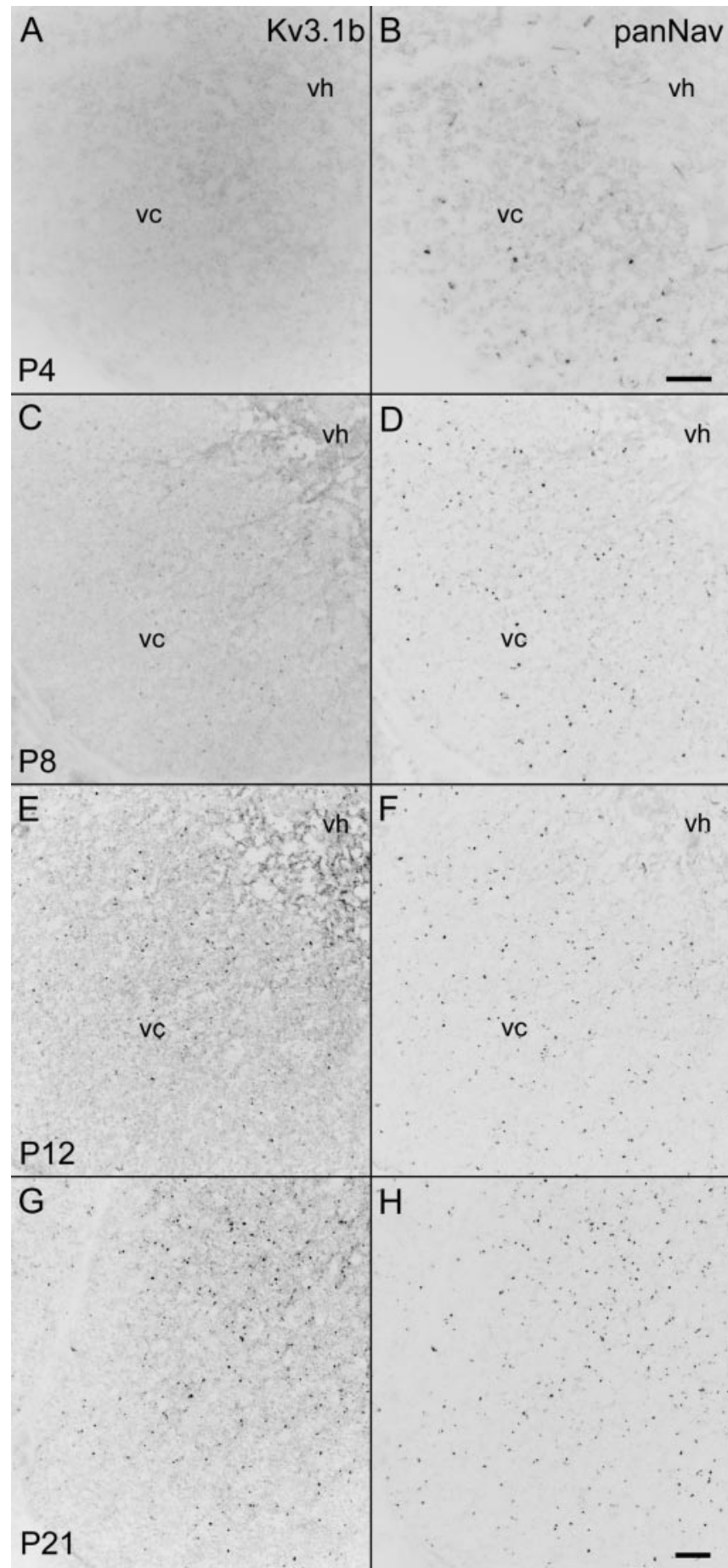

Figure 6. Delayed appearance of Kv3.1b at CNS nodes. These are images shown as negatives (the nodes are dark) of transverse sections of unfixed thoracic spinal cord from P4 (A, B); P8 (C, $D), P 12(E, F)$, and P21 $(G, H)$ rats. The ventral column (vc) is shown, as well as the ventral horn (vh) in A-F. At P4, $\mathrm{Na}_{\mathrm{v}}$ channels but not Kv3.1b channels were clustered. Kv3.1b clusters were present by $\mathrm{P} 8$, and their number, as well as that of $\mathrm{Na}_{\mathrm{v}}$ channels, increased from P4 to P21. At P21, nodes were labeled for both $\mathrm{Na}_{\mathrm{v}}$ channels and Kv3.1b. Scale bars: (in $\left.B\right) A, B, 20 \mu \mathrm{m}$; (in $H$ ) $B-H, 20 \mu \mathrm{m}$.

\section{Developmental expression of Kv3.1b}

Ankyrin G is the first molecular component that becomes localized in developing CNS nodes; $\mathrm{Na}_{\mathrm{v}}$ channels, $\mathrm{L} 1$, neurofascin and $\beta I V$-spectrin are recruited later (Jenkins and Bennett, 2001). To determine when Kv3.1b becomes localized to nodes, we immunostained transverse sections of the thoracic spinal cord from rats 

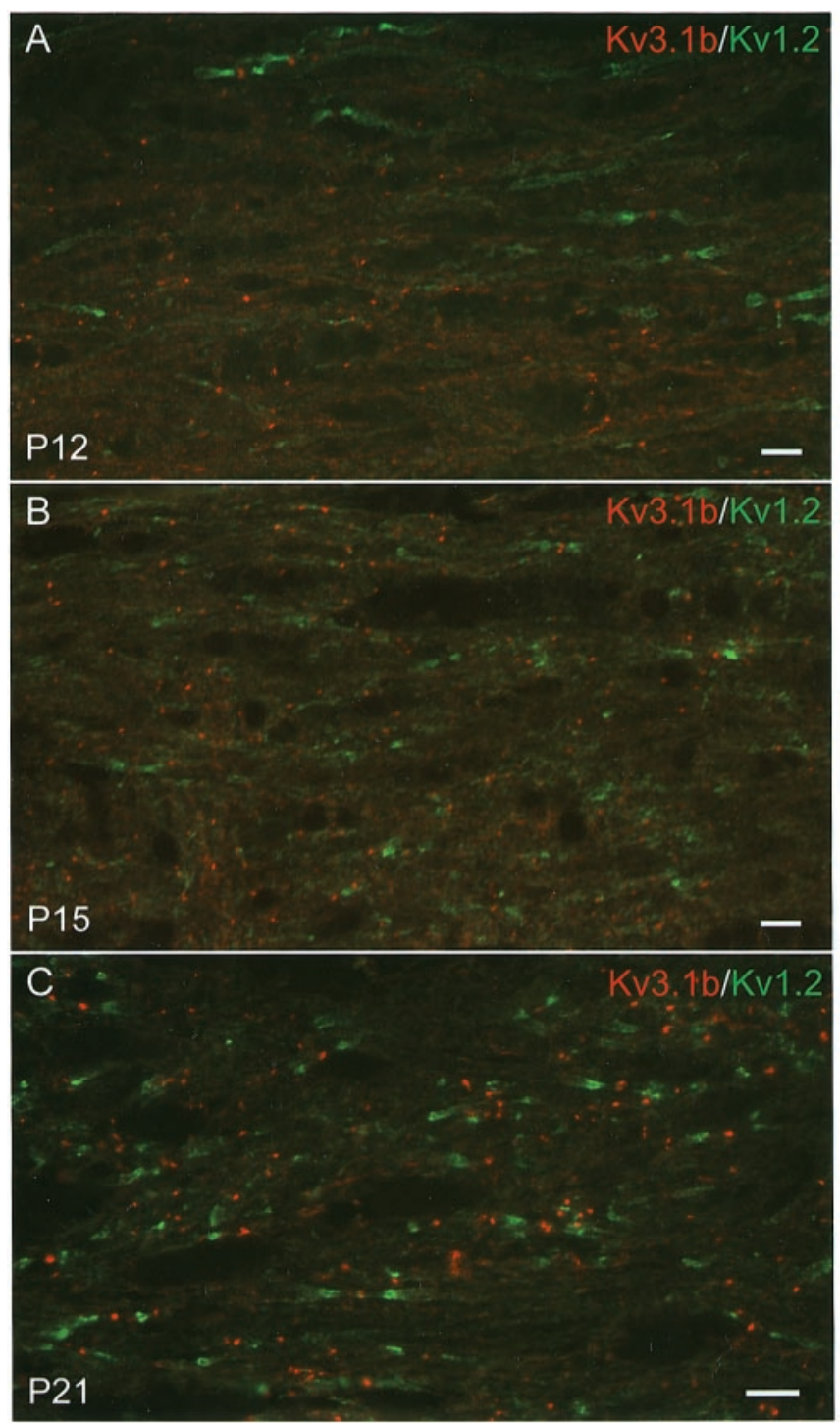

Figure 7. Kv3.1b appears before Kv1.2 in CNS myelinated fibers. These are longitudinal sections of the ventral column of unfixed rat ventral lumbar spinal cords at P12 $(A), \mathrm{P} 15(B)$, and P21 ( C). At P12 and P15, nodal Kv3.1b staining was often not associated with juxtaparanodal Kv1.2 staining, whereas at P21 most nodes were flanked by juxtaparanodal Kv1.2 labeling. Scale bars, $10 \mu \mathrm{m}$.

at $\mathrm{P} 4, \mathrm{P} 8, \mathrm{P} 12$, and $\mathrm{P} 21$. At $\mathrm{P} 4$, there were clusters of $\mathrm{Na}_{\mathrm{v}}$ channels in the ventral and lateral columns (Fig. $6 \mathrm{~B}$ ), but no Kv3.1b staining in the white matter or even the gray matter (Fig. 6A). At P8, there was weak Kv3.1b staining in the gray matter, and clusters of $\mathrm{Kv} 3.1 \mathrm{~b}$ in a minority of nodes in the ventral column (Fig. 6C,D). In longitudinal sections of the ventral column, Kv3.1b seemed to be selectively localized to "mature" nodes (short nodes rather than in elongated ones; Rasband et al., 1999a). At P12, the number, as well as the staining intensity of Kv3.1b-positive nodes increased markedly (Fig. 6E,F), and in longitudinal sections, $\mathrm{Kv} 3.1 \mathrm{~b}$ clusters appeared mostly in short, mature-appearing nodes (Fig. 7A). At P21, the distribution of Kv3.1b-positive nodes (Fig. 6G,H) appeared similar to that in adult rats.

We considered the possibility that Kv3.1b might cluster concomitantly with Kv1.1/Kv1.2 subunits. Kv1.1 and Kv1.2 are the last channels to be segregated in developing CNS (Rasband et al., 1999b), at approximately P8 in the spinal cord (Wang et al., 1995), and their clustering in the juxtaparanodal region depends on the formation of normal myelin sheaths, especially intact septate-like junctions (Baba et al., 1999; Mathis et al., 2001; Arroyo et al., 2002). Longitudinal sections through the ventral columns of lumbar spinal cords of P4, P8, P12, P15, and P21 rats were double labeled for Kv3.1b and Kv1.2. No staining for Kv1.2 was observed at P4 in the spinal cord, and few clusters of Kv1.2 were observed at P8 (data not shown). At P12, most Kv3.1bpositive nodes had no associated Kv1.2 staining (Fig. 7A). At P15, the proportion of Kv3.1b-positive nodes associated with Kv1.2 staining increased, and by P21 all Kv3.1b-positive nodes were flanked by juxtaparanodal Kv1.2 staining (Fig. 7B,C). Together, these results show that ion channel clustering in myelinated fibers follow the order: $\mathrm{Na}_{\mathrm{v}}$ channels, then Kv3.1b subunits, then Kv1.2 subunits.

\section{Does nodal clustering of $\mathrm{Kv} 3.1 \mathrm{~b}$ depend on myelination?}

To answer this question, we studied the localization of Kv3.1b in md rats, which typically die at approximately P21 from severe dysmyelination associated with oligodendrocyte cell death (Grinspan et al., 1998). Even at this age, few axons are myelinated in the spinal cord; axonal segments are ensheathed by few wraps of oligodendrocyte processes, which can be detected by their expression of MAG, or are totally devoid of ensheathment (Dentinger et al., 1982; Rosenbluth, 1987; Arroyo et al., 2002). Nevertheless, their spinal cords contain normal numbers of node-like clusters of $\mathrm{Na}_{\mathrm{v}}$ channels and ankyrin $\mathrm{G}$, even in regions devoid of oligodendrocytes (Arroyo et al., 2002). As shown in Figure $8, \mathrm{Kv} 3.1 \mathrm{~b}$ and $\mathrm{Na}_{\mathrm{v}}$ channels were colocalized in the spinal cord of $\mathrm{P} 21 \mathrm{md}$ rats $(A-C)$ and their age-matched WT littermates $(D-F)$. Double labeling for MAG demonstrated that some nodelike clusters of Kv3.1b were flanked by MAG-ensheathed segments, but many were found in unensheathed axonal segments (Fig. 8G). In contrast, the localization of the Kv1.2 subunits was highly altered in $m d$ rats: Kv1.2 subunits abutted the node-like clusters of Kv3.1b (Fig. $8 \mathrm{H}$ ) instead of being concentrated in the juxtaparanodal regions as in WT rats (Fig. $8 I$ ). These results show that node-like clusters of Kv3.1b behave similarly to clusters of $\mathrm{Na}_{\mathrm{v}}$ channels in $m d$ rats (Arroyo et al., 2002): both are formed during development and maintained at least temporarily even in the absence of myelin sheaths.

\section{$\mathrm{Kv} 3.1 \mathrm{~b}$ is associated with ankyrin $\mathrm{G}$ in brain membranes}

The colocalization of $\mathrm{Kv} 3.1 \mathrm{~b}, \mathrm{Na}_{\mathrm{v}}$ channels, and ankyrin $\mathrm{G}$ in CNS nodes suggested that Kv3.1b may interact directly or indirectly with ankyrin $\mathrm{G}$. The nodal isoforms of ankyrin $\mathrm{G}$ interact with several nodal proteins such as $\mathrm{Na}_{\mathrm{v}}$ channel $\alpha$ and $\beta$ subunits, neurofascin, and neural-glial-related CAM (NrCAM) (Malhotra et al., 2000; Bennett and Chen, 2001). To determine the level of expression of Kv3.1b and Kv3.2 in the brain, spinal cord, optic nerve, and sciatic nerve, we performed a Western blot analysis of these tissues (Fig. 9). Rat brain and spinal cord expressed more Kv3.1b than did optic nerve; Kv3.1b could not be detected in rat sciatic nerve; the above data are in keeping with the finding that CNS nodes have more robust Kv3.1b expression than do PNS nodes. The anti-Kv3.1b antiserum recognized a diffuse band of $\sim 85-105 \mathrm{kDa}$, significantly greater than the $66 \mathrm{kDa}$ expected for the Kv3.1b polypeptide obtained by translation of the Kv3.1b cDNA (Luneau et al., 1991), but in good agreement with the results of Weiser et al. (1995) on rat brain membranes. This band is almost certainly Kv3.1b, because it is absent in brain membranes from Kv3.1b-deficient mice (Fig. 9A). Kv3.2 was also detected in brain membranes, and to a lesser extent in the spinal cord, with a molecular weight range of $75-100 \mathrm{kDa}$ (Fig. 9B). 


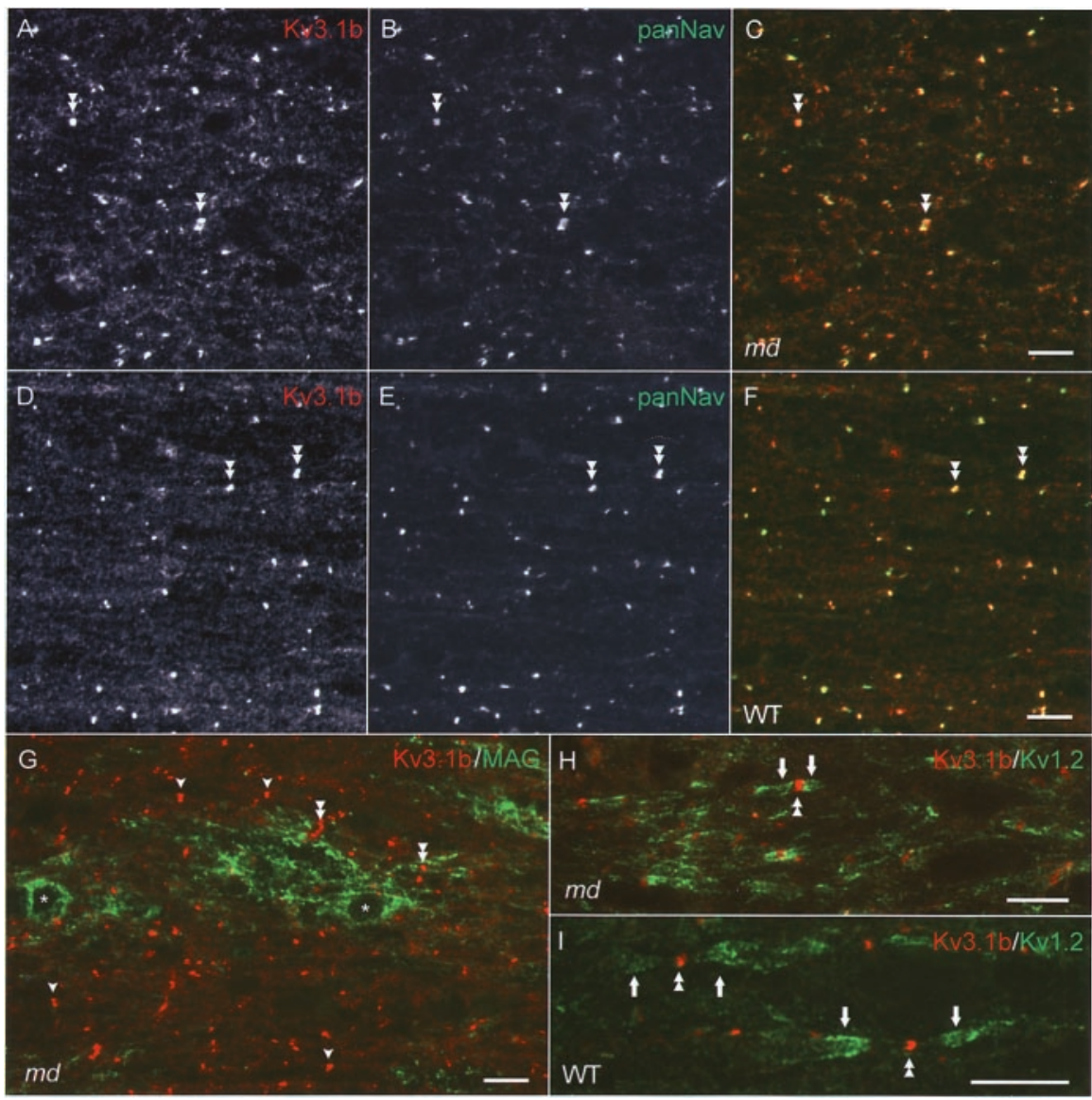

Figure 8. Node-like clusters of Kv3.1b in $m d$ rats. Longitudinal sections through the ventral funiculus of unfixed lumbar spinal cord from P21 $m d$ rats and their WT male littermates were double labeled with a rabbit Kv3.1b antiserum (TRITC) and a monoclonal antibody (FITC) against $\mathrm{Na}_{v}$ channels (pan $\mathrm{Na}_{v} ; A-F$ ), MAG ( $\left.G\right)$, or Kv1.2 (H, I). In $A-F$, note that in both $m d$ and WT rats, node-like clusters Kv3.1b colocalized with $\mathrm{Na}_{v}$ channels (double arrows). In $\mathrm{G}$, note that many node-like clusters of Kv3.1b (arrowheads) were found in regions devoid of MAG-positive oligodendrocyte processes. The asterisks mark oligodendrocyte nuclei. In $H$, I, note that the localization of Kv1.2 (arrows) was altered in $m d$ rats, abutting the node-like clusters of Kv3.1b (double arrows). Scale bars: (in C) $A-C, 10 \mu \mathrm{m}$; (in F) $D-F, 10 \mu \mathrm{m} ; G, 10 \mu \mathrm{m} ; H, 10 \mu \mathrm{m} ; I, 10 \mu \mathrm{m}$.

However, Kv3.2 was not detected in optic and sciatic nerves, in agreement with the immunostaining. We did not detect alterations in Kv3.2 staining in Kv3.1-deficient mouse spinal cord or brain; in particular, nodes were not Kv3.2-positive (data not shown). In addition, we did not detect any alterations in the labeling for contactin, Caspr, Kv1.1, ankyrin $\mathrm{G}$ or $\mathrm{Na}_{\mathrm{v}}$ channels (data not shown), suggesting that the absence of Kv3.1 does not alter the organization of these axonal proteins in myelinated fibers.

Because subunits of the voltage-dependent $\mathrm{K}^{+}$channels can form heteromeric channels with members of their own family (Kv1, Kv2, Kv3, and Kv4), we immunoprecipitated Kv3.2 to determine whether $\mathrm{Kv} 3.1 \mathrm{~b}$ and $\mathrm{Kv} 3.2$ subunits could interact. When Kv3.2 was precipitated, it pulled down more Kv3.1b in brain than in the spinal cord (Fig. 9C), in keeping with the relative lack of Kv3.2 in the spinal cord. These results indicate that Kv3.1bcould specifically form heteromeric channels with Kv3.2 in the CNS, but if they do, it is not at nodes.

To determine whether ankyrin G interacts with Kv3.1b, CNS membranes were incubated with antisera against ankyrin $G$ or $\mathrm{Kv} 3.1 \mathrm{~b}$, and the immunoprecipitates were probed for the same proteins. We used immunoprecipitates for Kv3.2 as a positive control and immunoprecipitates for Kv1.2 as a negative control. When ankyrin $G$ was precipitated from brain membranes, it pulled down Kv3.1b (Fig. 9D). However, Kv3.1b did not pull down high-molecularweight isoforms of ankyrin $\mathrm{G}$, but pulled down an isoform of ankyrin $\mathrm{G}$ of $\sim 97 \mathrm{kDa}$ (Fig. 9E). Neither Kv3.2 nor Kv1.2 coimmunoprecipitated this isoform of ankyrin $\mathrm{G}$ (Fig. 9E). Because ankyrin $\mathrm{G}$ is sensitive to proteolysis (Davis and Bennett, 1984), this isoform could correspond to a degradation product of the high-molecularweight nodal isoforms of ankyrin G. Alternatively, this result could indicate that an isoform of ankyrin $\mathrm{G}$ that is not localized to nodes interacts with Kv3.1b, because both ankyrin $\mathrm{G}$ and $\mathrm{Kv} 3.1 \mathrm{~b}$ are present in gray matter.

\section{Does Kv3.1b participate with AP repolarization in CNS nodes?}

To answer this question, we tested the effects of 4-AP, a potent blocker of Kv3.1b (Grissmer et al., 1994), on the CAPs recorded from sciatic nerve, spinal cord ventral funiculus, and optic nerve of adult rats. 4-AP slightly increased the duration of the CAPs of sciatic nerves (Fig. 10A), but broadened the CAPs recorded from the spinal cord ventral funiculus and optic nerve (Fig. $10 \mathrm{~A}$ ). The lack of effect of 4 -AP in the PNS could be attributable to the weak expression of $\mathrm{Kv} 3.1 \mathrm{~b}$ in sciatic nerve, but 4-AP affected the optic nerve, in which few nodes were Kv3.1b-positive. To resolve this discrepancy, we recorded CAPs from the optic nerves of Kv3.1-deficient and age-matched WT mice. CAPs recorded from WT and Kv3.1-deficient mice had similar onsets, peaks, and duration (Fig. $10 \mathrm{~B}$ ). The recruitment and refractory period of the fibers were also similar (data not shown). Moreover 4-AP broadened the CAPs from both the WT and the mutant mice (Fig. $10 \mathrm{~B}$ ). These results suggest that the effects of 4 -AP in the optic nerve axons are not mediated by Kv3.1; another nodal $\mathrm{K}^{+}$channel subunit could mediate these effects.

\section{Discussion}

\section{$\mathrm{Kv} 3.1 \mathrm{~b}$ is a nodal $\mathrm{K}^{+}$channel}

$\mathrm{Kv} 3.1 \mathrm{~b}$ is the first $\mathrm{K}^{+}$channel subunit to be identified in CNS nodes. Its heterogeneous expression in large nodes more than small nodes is reminiscent of the expression of $\mathrm{Na}_{\mathrm{v}} 1.6$ in distinct populations of CNS nodes (Arroyo et al., 2002). For example, in the corticospinal tract of the spinal cord, $\mathrm{Kv} 3.1 \mathrm{~b}$ and $\mathrm{Na}_{\mathrm{v}} 1.6$ are absent from the majority of the nodes, which are mainly immunopositive for $\mathrm{Na}_{\mathrm{v}}$ 1.2. These findings indicate that functionally distinct myelinated fibers may possess distinct ion channels at the nodes. Perhaps Kv3.1b repolarizes the AP of a population of CNS axons, akin to its apparent role in generating high-frequency responses in several neuronal populations (Rudy et al., 1999; Rudy and McBain, 2001)

The strong effect of 4-AP on the optic nerve of Kv3.1-deficient mice suggests that other $\mathrm{K}^{+}$channel subunits may be present in the nodal membrane. Because $\mathrm{K}^{+}$channels are composed of four subunits that can form homomeric or heteromeric channels with 
members of their own family, we considered the possibility that another Kv3 subunit, Kv3.2, was present at CNS nodes. $\mathrm{Kv} 3.2$ was a good candidate because it has the same electrophysiological characteristics as Kv3.1, and it can form heteromeric channels with Kv3.1 (Hernandez-Pineda et al., 1999). Our data demonstrate that this subunit is not present at nodes. However, Kv3.3 is another possibility, because it is coexpressed with Kv3.1b in several neuronal populations (Weiser et al., 1994). This possibility could explain the absence of major tremors in Kv3.1-null mice (Ho et al., 1997; Sanchez et al., 2000) and the important effect of 4-AP in the optic nerve, because the Kv3.3 subunit could palliate the absence of Kv3.1 in the nodes. Whether Kv3.3 is found at nodes, with or without $\mathrm{Kv} 3.1 \mathrm{~b}$, remains to be determined.

In the PNS, few nodes were Kv3.1bpositive, in keeping with the low density of I and F currents in PNS nodes (Safronov et al., 1993). Because 4-AP has weak effects on the sciatic nerve CAP it seems unlikely that another subunit of the Kv3 family is present at PNS nodes.

\section{Mechanisms of clustering of Kv3.1b}

Our immunoprecipitation results indicate that nodal ankyrin $\mathrm{G}$ isoforms may interact directly or indirectly with Kv3.1b. Several other proteins that are localized to nodes have been shown to interact directly with ankyrin G (neurofascin, $\mathrm{NrCAM}$, and $\mathrm{Na}_{\mathrm{v}}$ channel $\alpha$ and $\beta$ subunits) (Bennett and Chen, 2001; Bouzidi et al., 2002; Malhotra et al., 2002). However, the ankyrin-binding sequence of L1 CAM family members (Zhang et al., 1998a), CD44 (Bourguignon et al., 1998), and $\alpha-\mathrm{Na}^{+}, \mathrm{K}^{+}$-ATPase (Zhang et al., 1998b) did not reveal any obvious similarities to Kv3.1b (see Materials and Methods). Thus, the mechanism regulating the localization of $\mathrm{Kv} 3.1 \mathrm{~b}$ at $\mathrm{CNS}$ nodes remains to be determined. To our knowledge, no scaffolding protein has been described for Kv3.1 in any cell type.

The absence of Kv3.1b from initial segments and many small nodes is unexplained. No other protein has been shown to be expressed in nodes but not in initial segments because ankyrin $G$, neurofascin, $\mathrm{NrCAM}, \mathrm{Na}_{\mathrm{v}}$ channel $\alpha$ subunits, and $\beta \mathrm{IV}$-spectrin are all present in nodes and initial segments (Davis et al., 1996; Komada and Soriano, 2002). However, if the function of Kv3.1b is to repolarize the axon, this subunit may not be required in the initial segment.

Why Kv3.1b is more highly expressed in CNS than in PNS nodes is of interest, because this was apparent even on the same population of motor axons in the ventral root entry zone. We suspect that there are molecular interactions at CNS nodes that account for this discrepancy. Tenascin-R is a good candidate because it is an extracellular matrix molecule secreted by oligodendrocytes that is found at CNS nodes (for review, see Pesheva and Probstmeier, 2000). Contactin, a cell adhesion molecule, is yet another possibility, because it is present in adult CNS nodes and it associates with $\mathrm{Na}_{\mathrm{v}}$ channels and increases their functional expression in vitro (Kazarinova-Noyes et al., 2001).

\section{The organization of $\mathrm{K}^{+}$channels in $m d$ rats}

The nodal localization of Kv3.1b was maintained in $m d$ rats. In these rats, a mutant proteolipid protein kills oligodendrocytes as they mature (Grinspan et al., 1998). Node-like clusters of $\mathrm{Na}_{\mathrm{v}}$ channels form adjacent to incompletely formed paranodes and persist at least temporarily after oligodendrocyte death (Arroyo et al., 2002). These results are in keeping with the idea that a common molecular mechanism regulates the clustering of $\mathrm{Na}_{\mathrm{v}}$ subunits and Kv3.1b, even in dysmyelinating diseases. In dysmyelinating/demyelinating diseases, the safety factor for AP propagation is reduced because of the leakage of current through the denuded parts of the axon. The activation of Kv3.1b may reduce this safety factor further by decreasing the density of nodal currents that propagate. Thus, it is possible that Kv3.1b might interfere with conduction in demyelinated axons and that its blockade may favor the propagation of the AP. Therefore, our results open new perspectives for the treatment of demyelinating diseases.

\section{References}

Arroyo EJ, Scherer SS (2000) On the molecular architecture of myelinated fibers. Histochem Cell Biol 113:1-18.

Arroyo EJ, Xu T, Grinspan J, Lambert S, Levinson SR, Brophy PJ, Peles E, Scherer SS (2002) Genetic dysmyelination alters the molecular architecture of the nodal region. J Neurosci 22:1726-1737.

Baba H, Akita H, Ishibashi T, Inoue Y, Nakahira K, Ikenaka K (1999) Completion of myelin compaction, but not the attachment of oligodendroglial processes triggers $\mathrm{K}^{+}$channel clustering. J Neurosci Res 58:752-764.

Bennett V, Chen L (2001) Ankyrins and cellular targeting of diverse membrane proteins to physiological sites. Curr Opin Cell Biol 13:61-67.

Bhat MA, Rios JC, Lu Y, Garcia-Fresco GP, Ching W, St Martin M, Li JJ, 


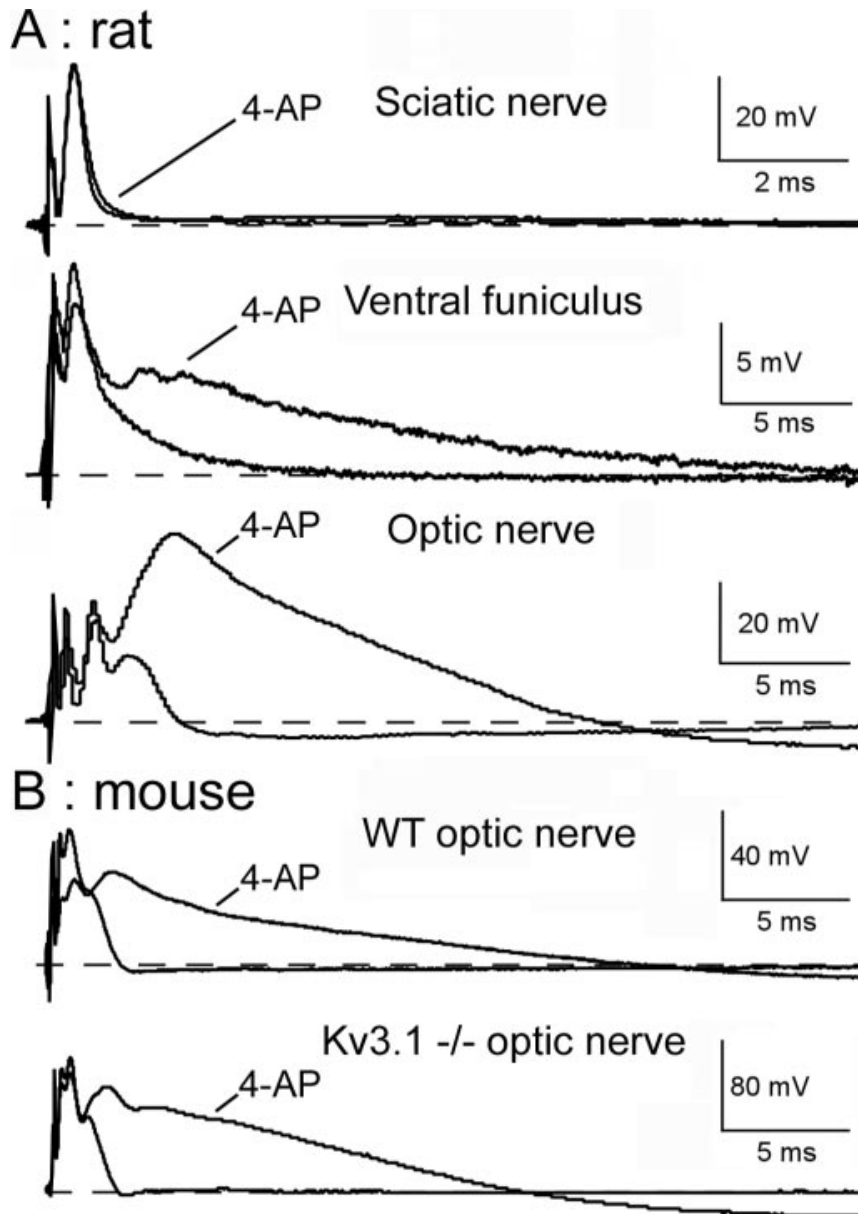

Figure 10. Effects of 4-AP on the CAPs of rat sciatic nerves, spinal cord ventral funiculi and optic nerves, as well as WT and Kv3.1-deficient mouse optic nerves. A, 4-AP (500 $\mu \mathrm{M})$ increased slightly the duration of the CAPs from rat sciatic nerves (top traces, $n=2$ ), but prolonged greatly the CAPs from the ventral funiculus (middle traces, $n=5$ ) and optic nerve (bottom traces, $n=6) \cdot B$, In WT $(n=2)$ and Kv3.1-deficient mice $(n=2)$, the characteristics of the optic nerve CAPs were identical, and 4-AP had similar effects.

Einheber S, Chesler M, Rosenbluth J, Salzer JL, Bellen HJ (2001) Axonglia interactions and the domain organization of myelinated axons requires Neurexin IV/Caspr/Paranodin. Neuron 30:369-383.

Bourguignon LY, Gunja-Smith Z, Iida N, Zhu HB, Young LJ, Muller WJ, Cardiff RD (1998) CD44v(3,8-10) is involved in cytoskeletonmediated tumor cell migration and matrix metalloproteinase (MMP-9) association in metastatic breast cancer cells. J Cell Physiol 176:206-215.

Bouzidi M, Tricaud N, Giraud P, Kordeli E, Caillol G, Deleuze C, Couraud F, Alcaraz G (2002) Interaction of the Nav1.2a subunit of the voltagedependent sodium channel with nodal ankyrinG: in vitro mapping of the interacting domains and association in synaptosomes. J Biol Chem 277:28996-29004.

Boyle MET, Berglund EO, Murai KK, Weber L, Peles E, Ranscht B (2001) Contactin orchestrates assembly of the septate-like junctions at the paranode in myelinated peripheral nerve. Neuron 30:385-397.

Chung K, Coggeshall RE (1987) Postnatal development of the rat dorsal funiculus. J Neurosci 7:972-977.

Davis JQ, Bennett V (1984) Brain ankyrin: a membrane-associated protein with binding sites for spectrin, tubulin, and the cytoplasmic domain of the erythrocyte anion channel. J Biol Chem 259:13550-13559.

Davis JQ, Lambert S, Bennett V (1996) Molecular composition of the node of Ranvier: identification of ankyrin-binding cell adhesion molecules neurofascin (mucin + third FNIII domain -) and NrCAM at nodal axon segments. J Cell Biol 135:1355-1367.

Dentinger MP, Barron KD, Csiza CK (1982) Ultrastructure of the central nervous system in a myelin deficient rat. J Neurocytol 11:671-691.

Devaux J, Gola M, Jacquet G, Crest M (2002) Effects of $\mathrm{K}^{+}$channel blockers on developing rat myelinated CNS axons: identification of four types of $\mathrm{K}^{+}$channels. J Neurophysiol 87:1376-1385.

Dupree JL, Girault JA, Popko B (1999) Axo-glial interactions regulate the localization of axonal paranodal proteins. J Cell Biol 147:1145-1151.

Eng DL, Gordon TR, Kocsis JD, Waxman SG (1988) Development of 4-AP and TEA sensitivities in mammalian myelinated nerve fibers. J Neurophysiol 60:2168-2179.

Gan L, Kaczmarek LK (1998) When, where, and how much? Expression of the Kv3.1 potassium channel in high-frequency firing neurons. J Neurobiol 37:69-79.

Gordon TR, Kocsis JD, Waxman SG (1988) Evidence for the presence of two types of potassium channels in the rat optic nerve. Brain Res 447:1-9.

Grinspan JB, Coulaloglou M, Beesley JS, Carpio D, Scherer SS (1998) Maturation-dependent apoptotic cell death of oligodendroglial cells in myelin-deficient rats. J Neurosci Res 54:623-634.

Grissmer S, Nguyen AN, Aiyar J, Hanson DC, Mather RJ, Gutman GA, Karmilowicz MJ, Auperin DD, Chandy KG (1994) Pharmacological characterization of five cloned voltage-gated $\mathrm{K}^{+}$channels, types Kv1.1, $1.2,1.3,1.5$, and 3.1 , stably expressed in mammalian cell lines. Mol Pharmacol 45:1227-1234.

Hartshorne RP, Catterall WA (1984) The sodium channel from rat brain: purification and subunit composition. J Biol Chem 259:1667-1675.

Hernandez-Pineda R, Chow A, Amarillo Y, Moreno H, Saganich M, VegaSaenz de Miera EC, Hernandez-Cruz A, Rudy B (1999) Kv3.1-Kv3.2 channels underlie a high-voltage-activating component of the delayed rectifier $\mathrm{K}^{+}$current in projecting neurons from the globus pallidus. J Neurophysiol 82:1512-1528.

Hildebrand C (1972) Evidence for a correlation between myelin period and number of myelin lamellae in fibres of the feline spinal cord white matter. J Neurocytol 1:223-232.

Ho CS, Grange RW, Joho RH (1997) Pleiotropic effects of a disrupted $\mathrm{K}^{+}$ channel gene: reduced body weight, impaired motor skill and muscle contraction, but no seizures. Proc Natl Acad Sci USA 94:1533-1538.

Honke K, Hirahara Y, Dupree J, Suzuki K, Popko B, Fukushima K, Fukushima J, Nagasawa T, Yoshida N, Wada Y, Taniguchi N (2002) Paranodal junction formation and spermatogenesis require sulfoglycolipids. Proc Natl Acad Sci USA 99:4227-4232.

Jenkins SM, Bennett V (2001) Ankyrin G coordinates assembly of the spectrin-based membrane skeleton, voltage-gated sodium channels, and L1 CAMs at Purkinje neuron initial segments. J Cell Biol 155:739-746.

Jenkins SM, Bennett V (2002) Developing nodes of Ranvier are defined by ankyrin $\mathrm{G}$ clustering and are independent of paranodal axoglial adhesion. Proc Natl Acad Sci USA 99:2303-2308.

Kazarinova-Noyes K, Malhotra JD, McEwen DP, Mattei LN, Berglund EO, Ranscht B, Levinson SR, Schachner M, Shrager P, Isom LL, Xiao Z-C (2001) Contactin associates with $\mathrm{Na}^{+}$channels and increases their functional expression. J Neurosci 21:7517-7525.

Kocsis JD, Ruiz JA, Waxman SG (1983) Maturation of mammalian myelinated fibers: changes in action-potential characteristics following 4-aminopyridine application. J Neurophysiol 50:449-463.

Komada M, Soriano P (2002) beta IV-spectrin regulates sodium channel clustering through ankyrin $\mathrm{G}$ at axon initial segments and nodes of Ranvier. J Cell Biol 156:337-348.

Luneau CJ, Williams JB, Marshall J, Levitan ES, Oliva C, Smith JS, Antanavage J, Folander K, Stein RB, Swanson R (1991) Alternative splicing contributes to $\mathrm{K}^{+}$channel diversity in the mammalian central nervous system. Proc Natl Acad Sci USA 88:3932-3936.

Malhotra JD, Kazen-Gillespie K, Hortsch M, Isom LL (2000) Sodium channel beta subunits mediate homophilic cell adhesion and recruit ankyrin to points of cell-cell contact. J Biol Chem 275:11383-11388.

Malhotra JD, Koopmann MC, Kazen-Gillespie KA, Fettman N, Hortsch M, Isom LL (2002) Structural requirements for interaction of sodium channel $\beta 1$ subunits with ankyrin. J Biol Chem 277:26681-26688.

Marcus J, Dupree JL, Popko B (2002) Myelin-associated glycoprotein and myelin galactolipids stabilize developing axo-glial interactions. J Cell Biol 156:567-577.

Matheson DF (1970) Some quantitative aspects of myelination of the optic nerve in rat. Brain Res 24:257-269.

Mathis C, Denisenko-Nehrbass N, Girault JA, Borrelli E (2001) Essential role of oligodendrocytes in the formation and maintenance of central nervous system nodal regions. Development 128:4881-4890.

Murray JA, Blakemore WF (1980) The relationship between internodal 
length and fibre diameter in the spinal cord of the cat. J Neurol Sci 45:29-41.

Ozaita A, Martone ME, Ellisman MH, Rudy B (2002) Differential subcellular localization of the two alternatively spliced isoforms of the Kv3.1 potassium channel subunit in brain. J Neurophysiol 88:394-408.

Peles E, Salzer JL (2000) Molecular domains of myelinated fibers. Curr Opin Neurobiol 10:558-565.

Perney TM, Marshall J, Martin KA, Hockfield S, Kaczmarek LK (1992) Expression of the mRNAs for the Kv3.1 potassium channel gene in the adult and developing rat brain. J Neurophysiol 68:756-766.

Pesheva P, Probstmeier R (2000) The yin and yang of tenascin-R in CNS development and pathology. Prog Neurobiol 61:465-493.

Rasband MN, Shrager P (2000) Ion channel sequestration in central nervous system axons. J Physiol (Lond) 525:63-73.

Rasband MN, Peles E, Trimmer JS, Levinson SR, Lux SE, Shrager P (1999a) Dependence of nodal sodium channel clustering on paranodal axoglial contact in the developing CNS. J Neurosci 19:7516-7528.

Rasband MN, Trimmer JS, Peles E, Levinson SR, Shrager P (1999b) K ${ }^{+}$ channel distribution and clustering in developing and hypomyelinated axons of the optic nerve. J Neurocytol 28:319-331.

Reid G, Scholz A, Bostock H, Vogel W (1999) Human axons contain at least five types of voltage-dependent potassium channels. J Physiol (Lond) 518:681-696

Rettig J, Wunder F, Stocker M, Lichtinghagen R, Mastiaux F, Beckh S, Kues W, Pedarzani P, Schroter KH, Ruppersberg JP, Veh R, Pongs O (1992) Characterization of a Shaw-related potassium channel family in rat brain. EMBO J 11:2473-2486.

Rosenbluth J (1987) Abnormal axoglial junctions in the myelin-deficient rat mutant. J Neurocytol 16:497-509.

Rudy B, Chow A, Lau D, Amarillo Y, Ozaita A, Saganich M, Moreno H, Nadal MS, Hernandez-Pineda R, Hernandez-Cruz A, Erisir A, Leonard C, VegaSaenz de Miera E (1999) Contributions of Kv3 channels to neuronal excitability. Ann N Y Acad Sci 868:304-343.

Rudy B, McBain CJ (2001) Kv3 channels: voltage-gated $\mathrm{K}^{+}$channels de- signed for high-frequency repetitive firing. Trends Neurosci 24:517-526. Safronov BV, Kampe K, Vogel W (1993) Single voltage-dependent potassium channels in rat peripheral nerve membrane. J Physiol (Lond) 460:675-691.

Sanchez JA, Ho CS, Vaughan DM, Garcia MC, Grange RW, Joho RH (2000) Muscle and motor-skill dysfunction in a $\mathrm{K}^{+}$channel-deficient mouse are not due to altered muscle excitability or fiber type but depend on the genetic background. Pflügers Arch 440:34-41.

Sekirnjak C, Martone ME, Weiser M, Deerinck T, Bueno E, Rudy B, Ellisman $\mathrm{M}$ (1997) Subcellular localization of the $\mathrm{K}^{+}$channel subunit Kv3.1b in selected rat CNS neurons. Brain Res 766:173-187.

Vabnick I, Trimmer JS, Schwarz TL, Levinson SR, Risal D, Shrager P (1999) Dynamic potassium channel distributions during axonal development prevent aberrant firing patterns. J Neurosci 19:747-758.

Wang H, Allen ML, Grigg JJ, Noebels JL, Tempel BL (1995) Hypomyelination alters $\mathrm{K}^{+}$channel expression in mouse mutants shiverer and Trembler. Neuron 15:1337-1347.

Weiser M, Vega-Saenz de Miera E, Kentros C, Moreno H, Franzen L, Hillman D, Baker H, Rudy B (1994) Differential expression of Shaw-related $\mathrm{K}^{+}$ channels in the rat CNS. J Neurosci 14:949-972.

Weiser M, Bueno E, Sekirnjak C, Martone ME, Baker H, Hillman D, Chen S, Thornhill W, Ellisman M, Rudy B (1995) The potassium channel subunit Kv3.1b is localized to somatic and axonal membranes of specific populations of CNS neurons. J Neurosci 15:4298-4314.

Zhang X, Davis JQ, Carpenter S, Bennett V (1998a) Structural requirements for association of neurofascin with ankyrin. J Biol Chem 273:30785-30794.

ZhangZ,DevarajanP,DorfmanAL, MorrowJS (1998b) Structureoftheankyrinbinding domain of alpha-Na,K-ATPase. J Biol Chem 273:18681-18684.

Zhou L, Zhang CL, Messing A, Chiu SY (1998) Temperature-sensitive neuromuscular transmission in Kv1.1 null mice: role of potassium channels under the myelin sheath in young nerves. J Neurosci 18:7200-7215.

Zhou L, Messing A, Chiu SY (1999) Determinants of excitability at transition zones in Kv1.1-deficient myelinated nerves. J Neurosci 19:57685781. 